\title{
MPR
}

Music Performance Research

Copyright (C) 2020

Royal Conservatoire of Scotland

Vol.10

$1-20$

ISSN 1755-9219

\section{Leading with score study: changing priorities in undergraduate conducting curricula}

\author{
Brian Kaufman \\ University of Maryland Baltimore County \\ Nell Flanders \\ Princeton Symphony Orchestra
}

\begin{abstract}
The purpose of this study was to examine student learning in an introductory conducting course in which score study was the primary foundational focus; gesture was viewed as part of a larger conducting process and a secondary learning goal to score study. Research has indicated a need for greater emphasis on score study in introductory conducting courses (Silvey, Springer, \& Eubanks, 2016; Stewart, 2011). Student reflection is often used to guide students in understanding the relationship of their gesture to the sound of a live ensemble; however, within the studied course, reflection was expanded to focus on the score study process - developing score study skills, practice habits, and concepts. Researchers analyzed student reflections $(N=25)$ in order to understand student learning and identify potential improvements to the course. Student reflections were coded using a general inductive approach. In their reflections, students discussed evaluating, revising, refining, and integrating approaches; making connections between conducting and other coursework; analyzing the conducting process; and developing their own conducting philosophy. A model that captures the students' collective learning process is described. Focusing on score study in this introductory conducting course resulted in substantial student learning about an array of conducting skills and concepts in relation to score study. Reflection assisted students in developing a score study process and a growth mindset, both of which support future learning. Findings provide a springboard for future research that examines how a comprehensive and integrated score study process occurring over time can best contribute to the learning of beginning conducting students.
\end{abstract}


KEY WORDS: score study skills and concepts, conducting learning goals, reflective practice, developing an aural image, model for conducting process

\section{INTRODUCTION}

Score study is a fundamental skill and the first step in preparing to conduct and rehearse, yet it seems to be treated cursorily in introductory conducting classes. A great deal of knowledge and skill is assumed, and the skills taught often do not fully reflect the working priorities of experts, such as professional conductors, university large ensemble directors, and undergraduate conducting teachers. So what is the importance of score study in an introductory conducting class? To what extent can beginning students learn and experience the scope of the conductor's craft? How can conducting teachers foster students' growth mindset in order to lay the groundwork for future learning? Engaging students in rigorous score study within an introductory conducting course offers valuable insights into these questions.

In this study, student learning was examined in an introductory undergraduate conducting course that prioritized intensive score study as a starting point for interpretation, gesture, and communication. Student development and understanding of foundational conducting skills and principles were assessed through analyzing students' written reflections. Past research makes clear the typical approaches to and challenges of score study in undergraduate conducting curricula in the United States and highlights the purpose and importance of score study as a foundational skill.

\section{Examining undergraduate conducting curricula}

Conducting pedagogues, regardless of whether they teach beginning or advanced classes, do not agree on appropriate sequencing of content in undergraduate conducting courses (Lane, 2006; Manfredo, 2008; Silvey, 2011). The expansive range of skills required to be a successful conductor may make it difficult to determine what to teach when and how (Kornelson, 2005). Sheldon (1998) describes the complex nature and scope of skills needed to be a successful conductor. Live conducting often requires a range of "tasks that occur either simultaneously or in rapid succession", such as:

aural instruction, vocal modeling, gestural or non-verbal instruction, listening to the ensemble, assessing aural response (what the ensemble plays) against visual cues (notation of the score), assessing aural response against personal conceptualization of music, evaluation of the assessment, development of conductor response, and delivery of response (feedback), and further instruction to the ensemble. (Sheldon, 1998, p. 384)

Preparation tasks may include:

playing parts or all of the score on a melodic instrument (acoustic or electronic), singing with solfege, singing without solfege, listening to recordings of live ensembles (full and chamber), listening to correct and altered aural referents, and audiating while reading the score silently. (Sheldon, 1998, pp. 385)

Historical background, analysis, knowledge of orchestral instruments, and transposition (Battisti \& Garofalo, 1990) are among other critical skills for successfully conducting an 
instrumental work. Conducting teachers face this exhaustive list of skills and must choose how to introduce, isolate, integrate, and sequence foundational conducting skills and concepts.

Silvey and Baumgartner (2016) noted that physical skill development, including expressive gesture, eye contact, and facial expression, is often the focus of introductory undergraduate conducting courses. As a result, "many students may choose to focus more on the physical act of conducting than on interpretative decision-making processes" (Silvey et al., 2016, p. 90). This may in part be due to the way beginning conducting textbooks are constructed. Stewart (2011) reviewed 13 undergraduate conducting textbooks, at least three of which - Hunsberger \& Ernst, Green \& Gibson, and Labuta - appear to be widely used in U.S. programs (Silvey et al., 2016). Stewart reported that the reviewed texts primarily focus on gesture, typically including only a single chapter on score study.

Introductory conducting courses may focus on gesture technique because those skills require significant practice time to develop (Gumm, 2012). However, there may be other reasons instructors focus on nonverbal skill development. Stewart (2011) concluded that introductory conducting instructors and textbook authors may assume that "other music courses have adequately prepared students in the areas of ear training, theory, history, style analysis, performance practice, and general knowledge of standard repertoire" (p. 28). Stewart (2011) expressed concern that conducting instructors may conclude that they need only support young conductors in the development of gesture. However, Sheldon (1998) writes that competencies developed in these other areas may not transfer to conducting contexts. Synthesizing the range of skills required also poses significant challenges to the beginning conductor (Mirakian, 2015).

\section{Comparing score study practices of conducting pedagogues with practices taught to undergraduates}

Research reveals discrepancies between the practices experts use in their own score study and those they teach to students. Silvey et al. (2016) studied U.S. undergraduate conducting teachers' attitudes towards score study, their personal score study practices, the score study strategies they taught their students, and the materials used to teach score study. They identified 21 score study approaches through a literature review. The top two reported approaches for both personal studies and strategies taught to students were "define all unfamiliar music terms" and "make an initial, casual read-through of the score", while the least reported approaches were to "reduce the score to its essential parts at the piano" and "input lines into notation software (e.g., Finale or Sibelius) for playback during score study" (Silvey et al., 2016, p. 89). However, beyond these approaches, undergraduate conducting teachers' habits differed from the approaches used to teach undergraduates; 17 practices were identified as being used more by instructors in personal study than when teaching beginning students.

Silvey et al. (2017) noted that a study by Zirkman (1984) suggested that many conducting teachers do not teach a particular method of score study, instead allowing students to select what may work best for them. Mitchell (2018), however, concludes that while there may be no universal process, teaching no method is a poor approach. Given that (a) score study is a foundational skill that supports a range of other aspects of conducting, (b) skills developed in other classes may not transfer, and (c) beginning undergraduate 
conducting students are unlikely to have enough reference points to understand the habits of mind of expert conductors, it seems that leaving students to figure out how to study a score is unlikely to succeed.

Lane (2006) concluded that conducting students should engage with conducting skills and concepts in ways that mirror experts' approaches and habits of mind. While conductors have diverse opinions on many conducting topics, Lane noted:

Most experts assert that intensive score study is the first step in preparing any piece of music and that it must occur well before rehearsals commence. Knowledge gained through score study provides the basis for musical interpretation, gesture, rehearsal planning, assessment, and evaluation. (Lane, 2006, p. 216)

Silvey et al. (2016) suggested score study should also be an educational priority for introductory conducting class teachers. The authors noted that instructors used a variety of sources in their own personal score study and suggested that a greater diversity of sources, such as "videos featuring prominent conductors, practitioner articles, handouts from conducting symposia" (Silvey, 2016, p. 92), might be used to teach score study.

The role of listening to recordings within the score study process is a good example of disagreement among conducting pedagogues (Battisti \& Garofalo, 1990; Hunsberger \& Ernst, 1992; Labuta, 2004; Maiello \& Bullock, 1996). Perspectives range from recommending against listening to recordings at all to having students listen to recordings throughout the score study process as a part of developing an overall conception of the piece. These differing beliefs about the use of recordings during the score study process appear to be reflected in the diversity of practices employed by university conductors (Feyes, 2017).

It is also helpful to consider some of the issues apparent in research on score study at the undergraduate level. Studies that examine students' process in learning a score often investigate a specific skill or approach to score study, such as error detection or gesture expressivity. For example, Crowe (1996) investigated beginning conducting students' ability to detect errors when employing four different score study approaches - "no score study, study with score alone, study with score and correct aural example, and score study at the keyboard" (p. 160). Most studies also appear to employ research designs where students' skills or thinking are examined over a relatively short period of time. For example, Silvey et al. (2017) examined undergraduate instrumental music education majors' score study practices during a 20-minute session. Although these studies have many useful findings and implications, the ways students study scores within this research do not fully reflect the time and integrated approaches that expert conductors use to learn scores, which should be seen as a significant limitation.

\section{Challenges of assessing process-driven learning}

Assessment may become more complex when greater emphasis is placed on the learning process. For example, Ulrich (2009) offered undergraduate conducting instructors four sequenced questions to assess student conductors:

1. Does the student-conductor know the score and the composer's intentions?

2. Is the student-conductor able to communicate these ideas to the ensemble?

3. Is the student-conductor critically listening to the sounds the group is making?

4. Is the student-conductor able to make effective and efficient corrections? (p. 52) 
The first question points toward successful score study as the first step, the second question investigates if the student conductor is communicating a developed aural image, and the third and fourth questions examine if the conductor is responding to the ensemble's performance.

The research discussed so far suggests that most introductory coursework focuses on Ulrich's second question, rather than the first. However, gesture alone is unlikely to be sufficient for determining a conductor's knowledge of the score - gesture can neither capture the full range and scope of the score study process nor reflect all the qualities of score study that create an aural image. Conductors must choose which aspects of the music to show at any moment. Furthermore, the aspects shown are not always intended to convey the expressive qualities of the music. A conductor might choose to beat clear time in a section where there is a concern about pulse or rhythmic integrity within the ensemble rather than show characteristics of the musical phrase. A gesture-focused course, therefore, may not fully allow instructors to address Ulrich's first assessment question.

Silvey et al. (2016) suggest that students should be held accountable for pre-rehearsal behaviors through assessment of score study practices. Proposed possibilities include "marked scores, form and analysis diagrams, or audio- and/or video-recorded instances of students' singing or performing lines on primary instruments" (Silvey et al. 2016, p. 93). Regarding future research, Silvey et al. (2016) advocate for studies that examine the preparation process. Instructors could then consider how research findings might inform course design - including "learning activities that would help better connect gestural practice, and rehearsal planning" (p. 90). To this end, Feyes (2017) suggests that to gain a deeper understanding, future studies need to examine the entire score study process.

Score study is one of the most challenging tasks a conductor undertakes. The literature on score study in introductory conducting courses does not appear to have examined what students might learn when comprehensive score study skills and concepts are the starting point of learning about conducting.

\section{RESEARCH AIMS AND COURSE STRUCTURE}

The aim of this research was to examine student learning within an introductory conducting class focused not primarily on gesture development, but rather on strategies, concepts, and approaches to in-depth score study. Qualitative data in the form of student reflective writing was analyzed to understand learning and inform decisions about future course design. Specific questions of interest included:

- In what ways would students understand conducting concepts and preparation processes?

- What skills would students develop?

- In what ways would students make connections between conducting-related skills, musical and gestural concepts, score preparation, the learning process, and leading a live ensemble? 
This case study examined skill development and learning from an integrated score study process that occurred throughout an entire semester. The research aimed to support new formats for inquiry into beginning students' learning through score study and to serve as a catalyst for innovation in designing undergraduate conducting curricula that prioritize score study.

The course examined in this study was an introductory undergraduate conducting course at a mid-size state university on the East Coast of the United States. One of the authors taught the class during this study using a modified version of the original course design; the class had been taught by the other author in the previous year. Students in the class $(N=25)$ were mostly third- or fourth-year undergraduate music majors, including instrumental and vocal performance, jazz, composition, music education, and music technology; 10 students were female and 15 male. The class, which was required for undergraduate music majors, met for two 75-minute class sessions per week for 14 weeks. Twenty-four of the 25 students had already completed the required four semesters of ear training, theory, and piano skills, though the instructor observed a wide range of musical literacy among the students - some students still struggled with clef reading. Score study skills were sequenced and prioritized in order to support students in their development of an interpretation, an aural image, gestures, and in leading an ensemble. The syllabus listed the following learning goals and values:

By the end of this course, students will be able to:

- Describe and implement a comprehensive process for learning and preparing to conduct a score (e.g., score study, score reading/transposition, learning about composer and piece, making interpretive decisions, creating an aural image of the piece)

- Display fundamentals of gesture (e.g., posture, basic beat patterns, staccato/legato, cueing, character, dynamic changes, tempo changes, rubato, fermatas)

- Demonstrate multitasking skills through a range of musicianship tasks (e.g., play piano and sing, conduct and sing, conduct while singing composite lines, etc.)

Key course values

1. Musicianship development - high musical standards

2. Process, practice, and preparation that leads to product

3. Reflective learning - students will be asked to critically reflect on conducting principles and their own development

Desired student values and skills

- Students should value deep, intensive musical study process for a score as the first step in conducting.

- Students should be able to apply basic conducting gestures to new types of music and conducting situations and problem solve in new conducting situations.

- Students should value comprehensive musical leadership (dynamic musical multitasking of aspects including tempos, cues, character, dynamic, tracking multiple lines, etc.).

Some of the basic skills practiced were transposition and clef reading; researching the history of the composers, pieces and musical style; analyzing musical structure, harmonies and textures; learning and practicing a system of score marking; discussing instrumentation and score layout; defining terms; and tracing a composite melody. 
At the beginning of the semester, students read about and compared the score study methods of Hunsberger and Ernst (1992), Battisti and Garofalo (1990), and Labuta (2004), as well as those of the instructor. In addition, students watched a video of a rehearsal led by Sir Simon Rattle and made inferences about likely score study practices that supported the successful rehearsal strategies they identified. Over the course of the semester students learned two wind ensemble scores of 3-5 minutes in length. Each student conducted one practice session and one run-through of each score. They also completed assignments that aimed to build an in-depth knowledge of the scores. Exercises were used to solidify, integrate, and internalize students' knowledge of the score, leading them to develop their own aural image and interpretation of the music.

In the first part of the semester, students were divided into groups and studied either Copland's Down a Country Lane, Mussorgsky's "Promenade" from Pictures at an Exhibition, or an excerpt from Ravel's "Petit Poucet" from Ma Mère L'Oye. These works were chosen for their brevity, lack of transitions, and their complexity of phrase structure, which ensured that students would need to internalize and actively audiate the music as they conducted. Students studied and conducted one work while observing their peers on two other works; this enabled them to experience multiple styles and challenges while learning a more manageable amount of material. During the second part of the semester, all of the students studied the introduction of Suppé's Overture from Morning, Noon, and Night in Vienna. This work included challenges such as abrupt changes in tempo and character, more difficult transitions, changes in ensemble texture, and a larger instrumentation. Wind ensemble arrangements of all pieces were used to help students become familiar with $\mathrm{Bb}, \mathrm{Eb}$, and $\mathrm{F}$ transposing instruments.

As a step towards developing an aural image of the music, students made videos of themselves singing individual parts, playing melodic lines on an instrument, playing parts on the piano, singing and playing, and conducting while singing. This included both performing single lines of the score and jumping between different lines with different clefs and transpositions. Over the course of the semester, students submitted nine assignments, typically consisting of one or two videos. The exercises in these videos aimed to:

- help students learn and reproduce the primary melodic and accompanimental material,

- help students integrate this material into a composite aural image through multitasking exercises, and

- allow the instructor to assess how well the material had been learned.

At the end of the process, students submitted a video of themselves conducting the complete excerpt while singing the composite line of primary melodic material.

The aural image students developed through score study served as the basis for learning to communicate with the ensemble through gesture. The foundational vocabulary of gesture they learned included such skills as beat patterns, preparatory beats, cutoffs, cues, subito dynamic changes, articulations, fermatas, quality of sound, and phrase direction. Non-verbal communication was addressed by including cues and eye contact with imaginary players as part of the gesture practice. Students also received individual gesture coaching outside of class and developed their communication skills by conducting their peers in fourpart vocal harmony exercises.

Students were asked to reflect on their preparation process, video assignments, time 
conducting the ensemble, video footage, and the feedback they received. While limited classroom time did not allow students to rehearse or perform with the ensemble, they were encouraged to consider the implications of their preparation for a future rehearsal process. Additionally, students learned from observing their peers leading the ensemble. In addition to helping students develop comprehensive score study approaches, the instructor aimed for score study to support student success during their limited podium time.

Within conducting, reflection is often used to analyze the effectiveness of gesture with a live ensemble and to assess a range of factors that may contribute to rehearsal quality (Silvey \& Montemayor, 2014). However, in this course, reflections focused on metacognition. The aim of these reflections was to identify and advance students' thinking about score skills, approaches, and concepts as related to other parts of the conducting process. Students reflected on readings, their experiences preparing and performing the score study video assignments, and their experiences conducting the ensemble - prompting them to draw connections between developing score study skills, gesture, and communication with the ensemble. These written reflections were designed to help students to understand, refine, and direct their future work; they were also used to assess student progress and learning during the semester. The reflections also highlighted student understanding of how to develop an aural image, and the impact of doing so on their conducting practice. Students were informally assessed on other approaches to score study, including score marking, analysis, and historical study of the works. The final exam was a written assessment that prompted students to discuss the different skills, concepts, process, and approaches developed throughout the course.

A general inductive approach was employed in this study allowing themes to emerge from the raw data through the coding process (see Thomas, 2006, pp. 238-239). Data analyzed in the study included the written reflections students submitted throughout the semester in response to all readings, assignments, tests, and in-class conducting experiences. The written final examination, which prompted students to reflect on and synthesize their learning from the course, was also included. The following prompt from video assignments and tests conveys the type of information requested of students in their reflective writing:

What did you learn about the conducting process from completing this assignment? What are the implications for future conducting? (While you aren't expected to answer all of these, some questions to consider are: What questions were raised for you? What surprised you? What practices or ideas do you hope to utilize in the future, or how might you proceed differently in the future? What strengths and weaknesses did you exhibit? You are encouraged to tie your ideas to past course assignments, in class work, and/or your learning in other music classes.)

Prompts were written in a broad, open-ended manner to allow students to share their individual thinking, as opposed to soliciting a specific desired answer.

More than 240 pages of single-spaced text were read, re-read, and annotated. The review included analyzing the evolution of thinking of individual students as well as identifying themes collectively discussed by participants. Categories were developed, and two models were then created to capture the processes and approaches collectively described by students in the course. 


\section{FINDINGS}

Students discussed a broad range of topics in their reflections. Analysis revealed five themes that they consistently wrote about:

- practice habits and skill building,

- the process of developing an aural image,

- developing gesture from the aural image,

- connecting score preparation to working with a live ensemble, and

- approaches to future learning.

\section{Practice habits and skill-building}

In response to video assignments and in-class conducting experiences, students evaluated their knowledge of the material and their ability to perform, integrate, and apply the skills needed to prepare and conduct a piece. Comments often focused on the development of effective study and practice habits as students grappled with the challenge of learning and internalizing an orchestral score for the first time. Although 24 of the 25 students had completed the required musicianship courses, their reflections suggested substantial differences of competency in aural skills, reading literacy, theoretical analysis, and keyboard skills; as a result, practice time appeared to differ based on individual strengths and weaknesses. Names in the summary below are identified by pseudonyms that correlate to each student's sex.

At the beginning of the semester, all 25 of the students expressed frustration at the difficulty of the assignments. For example, Carol wrote:

\footnotetext{
At first, I was completely overwhelmed, and I didn't know where to start. As time went on, I realized that I had to work on things bit by bit and break it down in a way that made sense to me... learned that my usual manner of doing things (just jump right in and figure it out as I go) wasn't working and probably isn't the best way to do things going forward.
}

As the semester progressed, the students observed that they were developing strategies to learn the material more efficiently. They cited strategies such as working through small sections of a piece before putting the sections together, practicing slowly, repeating sections, and practicing isolated skills before combining them in progressively more challenging combinations (such as singing; then singing and conducting a beat pattern; then singing, conducting the beat pattern, and cueing).

Most video assignments required students to sing sections of the music and then combine singing with conducting. While some students enjoyed singing and found it productive, many expressed frustration with their inability to sing accurately, expressively, in tune, or with a sufficiently wide range. These students often noted how much easier and more fruitful it was for them to perform the melody on their own instruments. Reading multiple clefs and transposed parts appeared to contribute to the challenge of performing these lines successfully, though students indicated that they became more fluent as they progressed through the course.

Students often described the challenge of integrating the different skills that they were developing; however, they also said they experienced gradual progress in managing this challenge through improving their practice habits. Most suggested that the required tasks 
were more complex than previous coursework. Jeff, for example, wrote:

By singing through the parts, I was able to both internalize motivic material and get a better sense of the direction of the phrases in general. I also still find myself struggling with singing the parts and conducting them at the same time. However, I am getting better at doing them individually; my singing of the lines is improving by listening and playing them on the piano, and my conducting is getting more natural with repetition.

\title{
The process of developing an aural image
}

Annotating and singing composite melodies appeared to provide students with a manageable starting point for developing an aural image - a foundation on which to build a more comprehensive hearing of the score. This was particularly evident for students who expressed frustration with performing multiple parts of the score simultaneously. Furthermore, 19 of the students mentioned that recordings helped them learn the score. This was notable, because listening was not a strategy assigned by the instructor. Those who used recordings also discussed struggling to complete the assignments and found recordings helpful for both accuracy and saving time.

Seventeen students commented that performing parts in different ways helped them to gain a clearer aural image, make interpretive decisions, and better understand the work. For example, Michael wrote:

\begin{abstract}
I found it very helpful to play this section of the piece on the piano with the full harmony and melody. I feel that doing this exercise helped me to solidify my mental conception of this passage's character. When I had just played the melody alone for [the 20-measure clarinet solo from Suppé's Morning, Noon, and Night in Vienna], I didn't really feel the character of the passage in the context of the rest of the piece. I think that playing the piece on an instrument will allow me to make a more informed choice about what tempo I take for the various sections. Hopefully, now that I am more familiar with this passage, I will be able to make clearer, more accurate gestures for the performers.
\end{abstract}

Thirteen of the 25 students acknowledged the importance of transitioning from studying and learning the details of the individual parts to synthesizing this information into a more comprehensive aural image. Partway through the course, Lewis wrote, "I finally started to grasp the idea that conductors must be digesting the score whole; that is, observing every detail of what is transpiring and articulating it at once". While it appeared that not all students achieved this level of conceptual understanding, those students who articulated greater success with synthesis expressed relief and a greater ability to manage the material, develop appropriate gestures, and interact successfully with the ensemble. The 12 students who did not mention the synthesized aural image appeared to be more focused on individual elements of score reading and gesture.

Students seemed to grasp the importance of the conductor's musical vision and interpretive decisions regarding many aspects of interpretation, including tempo, character, timing, dynamics, and phrasing in achieving effective leadership, though they were sometimes perplexed by the process of how to arrive at these interpretive decisions. However, as the course progressed, students discussed interpretation and internalization earlier in the learning process, and a more creative and artistic mindset seemed to connect with increased confidence and enjoyment.

Developing gesture from the aural image 
Nineteen of the students commented on the substantial amount of time required to develop an aural image and then communicate it through expressive gestures. They discussed how internalization of the aural image generated gesture and facilitated communication with the ensemble as their understanding of the score moved from an analytical understanding to an experiential one. Partway through the semester, Steve wrote in response to his work on a video assignment:

I learned how important it is that I dedicate time in the future for working on and internalizing the music well before I add in the conducting gesture aspects. I feel at least for me, it must be strong inside my head before I can communicate it through my hands.

The same student later observed how gesture itself could aid with this process of internalization:

It is much clearer to me than before how my actions as a conductor will shape the sound of the ensemble. I believe this helped me internalize this section of the piece much faster because I had to be aware of my actions and make decisions about how I wanted to express and interpret the piece.

Jeff conveyed additional insights:

The movements of the conductor should be a direct reflection of the internal concept the conductor has of the music. For me, this means that preparatory gestures, cut offs, fermatas, etc., ought to match the style of the music. The quality of sound the conductor expects should match the quality of gesture the conductor provides.

With this comment, Jeff shows a nuanced understanding of the connection between aural image and gesture.

Fourteen of the students commented on how developing expressive gestures became easier as they generated a clearer aural image, and how a well-defined aural image contributed to greater musical engagement. When they had a clear aural image of the music, they felt a greater sense of ease, both physically and in their thought process and coordination. Wendy observed:

One thing I've noticed is that the more I practice the parts musically, the more I can focus on the gesture, and when I struggle with the pitches, rhythm, or transpositions, the quality of my gesture goes down as well.

And Kate wrote:

I found the more I knew the piece, the more I could actually work on the musical aspects of the piece. I was very surprised at how difficult it was to communicate what your intentions are through your hands. I also found the more relaxed I was, the easier I could feel the music and the smoother the conducting.

These observations reflect connections made between gesture, expression, and sound, which may emerge differently than when gestural vocabulary is developed separately from its expressive purpose. Wendy shared the following:

Now that I'm better at consistently cueing instruments, I'm working on making the shape of the gesture I use to cue the instrument more specific to what sound they should be coming in with instead of just pointing or nodding at everyone.

While still challenged by the coordination required to maintain beat patterns, give cues, and show specific information such as dynamics, sound, and articulations, Wendy 
articulated an appreciation of the connection between the gestures and the sound in her mind's ear.

\section{Connecting score preparation to working with a live ensemble}

Student reflections suggested that meaningful learning had occurred during the four opportunities to conduct the ensemble. Noting the impact of his gestures, Arnold wrote, "I learned that the clearer I made my movements, the better response I had". Eleven of the students noted the degree to which their confidence impacted the quality of their conducting. Performing in the ensemble when their peers conducted appeared to provide important insights about the relationship between conductor and ensemble. Mark wrote from his perspective in the ensemble about the need for self-efficacy:

I noticed that the students who were the most confident in their conducting...had the best sounding runs of the score. People that let their fears and unease show on their face had sloppier runs.

Recurring comments were also made about the effectiveness of gesture, importance and challenge of making eye contact, and the visual effect of eye contact. Other aspects of communication with the ensemble that the students mentioned were gesture effectiveness, the importance and challenge of making eye contact, and the visual effect of posture.

While rehearsal technique was not the focus of student podium time in this course, students were able to make astute observations about how the content they had studied would be beneficial in this area. The final exam prompted students to consider how their knowledge and skill in score study would help them to guide a rehearsal. David wrote:

The only way I can make the ensemble do what I want is by understanding exactly what I want before I conduct them. It was clear that I had to know exactly what I was looking for in the ensemble and hear the sound I was looking for before I began.

There were also frequent comments about the correlation between score study and the ability to rehearse, with students identifying the importance of clear musical vision, clarity of gesture, anticipating problems and detecting errors, and understanding both balance and sound. Lewis wrote:

\footnotetext{
Through score study we not only learn the individual parts, but how they fit together as a whole and the harmonic progressions they create. This may help us deal with both individual issues and section/ensemble problems. We can recognize incorrect chords after having played them on the piano. In addition, we can identify when musicians miss their entrances or play an incorrect note or rhythm. The more work a conductor puts into their score study, the finer the details to be tackled in group rehearsals... [Score study] will help develop my own personal sound concept as I am more familiar with the piece, so I will be more decisive in which parts are brought out and which moods should be emphasized.
}

Like Lewis, many of the novice conductors recognized that developing a clearer aural image through score study can result in a more detailed rehearsal and a more refined ensemble performance.

\section{Approaches to future learning}

Reflections showed that the process of studying a score and developing an aural image 
differed according to each student's unique set of skills and experiences. Students often recognized which exercises and approaches they found most effective. As a result, they appeared to develop individual approaches and philosophies to score study and conducting. Students also came away with an appreciation of the complexity and scope of skills needed to conduct an ensemble successfully. While many had expressed a sense of being overwhelmed by the complexity of the conductor's work early in the semester, by the end they appeared to develop a growth mindset - acknowledging their progress and expressing optimism about their capacity to improve with continued effort (O'Neill, 2011). As Jason put it:

My understanding of the role of conductor has definitely changed since the beginning of the course. The amount of behind-the-scenes work required before the first rehearsal was something that I had not considered at all...I am actually a little terrified if I have to conduct a group in the future, but I know for sure that I have all the skills that I can be baseline successful and access to resources that I need to take it to the next level!

Jason's comment demonstrates not only the development of a growth mindset, but also some understanding of the scope of preparation needed to successfully support a live ensemble.

Many students commented on the usefulness of the practice approaches they learned in the class and their intention to continue to develop these skills, applying them to both future score study and work on their primary instrument. For example, Sarah wrote:

I feel as though the most important skill I learned in this class was effective score study and analysis. In my own pieces, I do not always thoroughly analyze them and spend time with the score. By using the score study techniques I have learned in this class, I can be more prepared to learn pieces already knowing how I want to play them. In-depth analysis can also help me with memorization, as knowing the piece theoretically is helpful if I forget a part of the music.

Other students identified reflection as a useful tool for their learning more broadly. Mark shared:

While I don't plan on conducting like this in the future, I think the idea of introspective reflection can be applied to just about everything I do in the future, whether it be drumming, singing, tech applications, you name it.

Students were able to make connections about how they could apply learning methods in the class to meet their musical goals in other contexts.

\section{Model of learning}

A process for studying scores emerged from the descriptions of student learning and experiences, the course design, and instructor approaches to score study. Figure 1 aims to capture the collective student experience, though it does not reflect the nuanced experiences of each individual. Students' score study process began with an analysis of the studied work, which included a theoretical analysis and research about the composer, piece, and historical context. Students then began performing the score in different ways, including various combinations of singing, conducting, and playing parts of the score. Students initially described the multi-tasking elements of these activities as challenging, though later in the semester, as their skills improved, they were more likely to identify these tasks as more manageable and useful for internalizing the music. Listening to recordings, 
score marking, and silent study contributed to both students' analysis and performance of the score; collectively, these actions led towards developing an interpretation and aural image. From the aural image as well as through performing different lines of the score, students described developing and refining gestures that reflected their musical ideas. Many students cited that their confidence in their gestures grew as they clarified their interpretation and aural image.

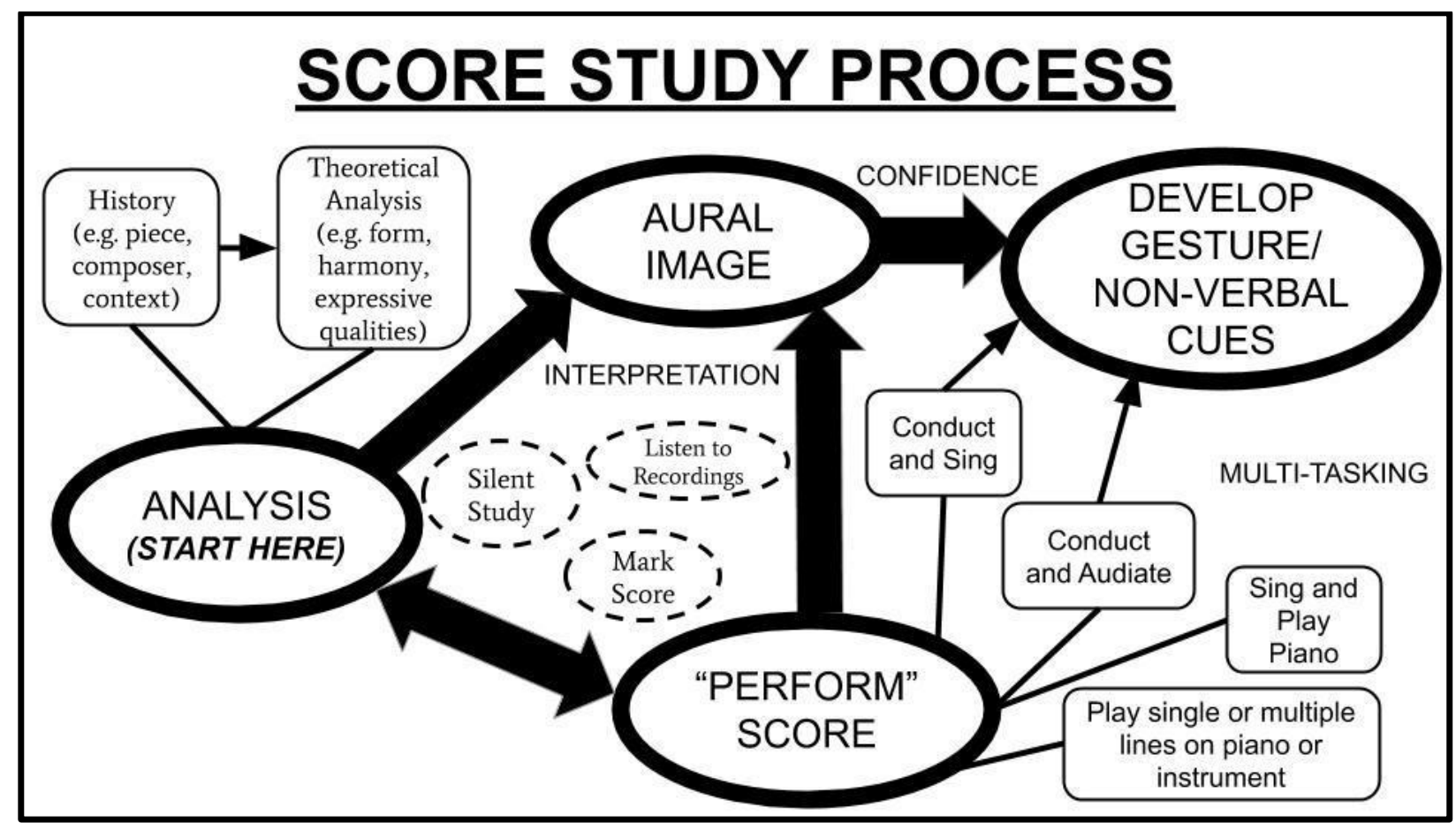

Figure 1. Score study process developed from student reflections and course design

Figure 2 illustrates a larger conducting learning process described by students. Score study appeared to have a bidirectional relationship with developing an interpretation, aural image, and gesture. This work all occurred off the podium, but directly influenced student actions and thinking on the podium with a live ensemble. Issues that emerged when they conducted the ensemble appeared to impact subsequent preparation practices. Reflection was the thread that connected students' time on and off the podium. In their reflections, students:

- assessed and evaluated different approaches;

- made connections between different conducting concepts;

- analyzed the entire conducting process as they experienced it;

- revised, refined, and integrated various approaches;

- developed their own philosophy for conducting, including identifying strategies that had not been assigned in the course; and

- identified applications of their learning in other contexts, such as in practice on their own instrument.

It should be noted that there was significant variation in individual ability and understanding of the aspects described within this process. Overall, the models for the 
score study process and broader conducting learning process may be useful frameworks for future conducting courses. Given the variation within student experiences and the limitation of a single semester with just 25 student participants, these should be seen as models that may be refined and adapted in future conducting curricula based on student needs and desired learning goals.

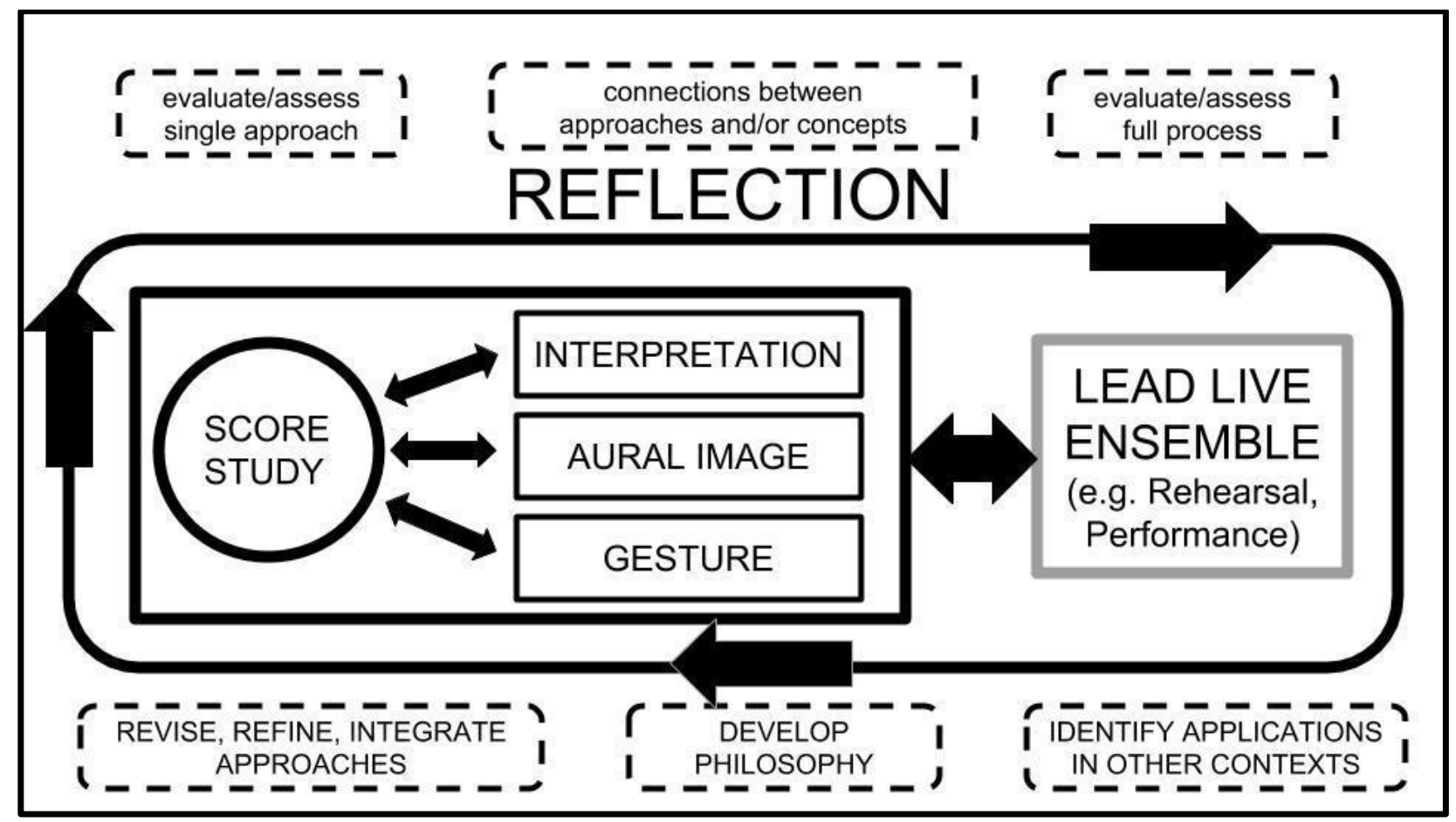

Figure 2. Conducting learning process as described in student reflections

\section{DISCUSSION AND IMPLICATIONS FOR PRACTICE AND RESEARCH}

This study has generated several implications for pedagogy and curricula in introductory undergraduate conducting courses. A breadth of skills and conceptual understanding emerged for students in the studied course, including the ability to: 
- study, internalize, make meaning of, and interpret a score;

- identify and advance approaches to practicing within the context of the score study process;

- conceptually understand and form an aural image;

- develop gesture that is informed by score study and aural image;

- synthesize and understand skills within a process of preparing to lead and then leading an ensemble;

- describe processes and components of score study within a larger conducting process;

- make connections with and identify applications to learning in other areas;

- develop an individual philosophy and approach to score study through exploring a range of different score preparation strategies; and

- develop a growth mindset that reflects students' ability to envision how acquired skills can apply to future learning.

Collectively, the learning processes described by students and modeled in the previous section appeared to mirror ways in which expert conductors approach conducting (Silvey et al., 2016). The development of these skills seemed to lead to a more realistic understanding of the competencies expected from a conductor, which may better support students in their future conducting studies.

Mastering the craft of conducting cannot be accomplished in a single semester, regardless of the focus of the course. Students may be best served by a beginning undergraduate course that helps them learn a process that places significant emphasis on score study and reflects approaches and habits of mind of expert conductors. Students could expect to leave an introductory class having developed a broad range of non-verbal conducting communication and study skills, an understanding of the scope of the conductor's role, and, through reflection, a process that connects preparation with leading a live ensemble.

While it appears such an approach would be beneficial, both teachers and students must wrestle with many tensions - for example, balancing the isolation versus the integration of skills, negotiating the focus on breadth versus depth of skills and concepts, and building conceptual understanding versus skills. In addition to these tensions, practical considerations may need to be made about skills specific to students within certain degree programs, such as music education. Deep integration between conducting classes and other coursework may help to focus curricula and better enable students to transfer skills and concepts.

Silvey et al. (2017) suggest that incorporating listening to recordings as part of a score study process could benefit beginning conducting students. In the current study, it was noteworthy that 19 students mentioned listening to recordings as part of their score study, particularly because the approach had not been assigned. Students indicated that model recordings, in conjunction with the other score study approaches, helped them to develop an aural image and interpretation. However, learning a score by only listening to a recording can be superficial because many details, layers, and nuances are easily missed. To ensure that students are not simply adopting an interpretation from a recording, conducting instructors may consider guiding students in critical listening strategies. On the other hand, both graduate and undergraduate students appear to have difficulty developing an aural 
image without recordings (Mitchell, 2018). Therefore, substantial time needs to be given to developing and integrating other score study skills, such as those employed in the examined course.

It was striking that most students did not feel successful or fully value the breadth of skills they were learning until they began studying the second work. The stress students experienced in the first part of the course might have been mitigated by having the class work together on a single work. Establishing a longer view of learning is important when placing an emphasis on score study, which can be supported through fostering a growth mindset. Dweck (2016) discusses how students with a growth mindset "take on more challenges, persist longer, and are more resilient in the face of setbacks" (p. 38). To develop a growth mindset, conducting instructors should focus on students' learning process rather than their abilities and help students link successes to their hard work and good strategies. When students fall short in achieving a task, educators should recognize effort but point towards a next step (Dweck, 2016). Recognizing the importance of mistakes, helping students to articulate their thinking process, and discussing how learning happens in steps through incremental progress and revision are all important for a process-focused approach to learning (Haimovitz \& Dweck, 2017).

Assessment of student learning was another issue that emerged throughout this study. The findings from this study suggest a need for further exploration and development of assessment within conducting curricula. Donovan et al. (1999) suggest that:

\footnotetext{
[Ongoing assessments] permit the teacher to grasp the students' preconceptions, understand where the students are in the "developmental corridor" from informal to formal thinking, and design instruction accordingly.... these assessments should provide students with opportunities to revise and improve their thinking (Vye et al., 1998b), help students see their own progress over the course of weeks or months, and help teachers identify problems that need to be remedied (problems that may not be visible without the assessments). (p. 21)
}

In the studied course, students discussed the preparation process in their reflections and linked it to other aspects of score study and conducting. These reflections provided insight into learning challenges, students' thinking about key concepts, and approaches that students found most effective in supporting their learning. Consistent reflections made visible the evolution of student thinking. In a process-focused course that emphasizes score study, reflections on the learning process should be utilized in addition to reflections on the relationship of gesture to sound during work with a live ensemble.

Students' engagement in writing reflections on all parts of their learning throughout the semester appears to have resulted in substantial benefit to their learning - helping them to problem solve, refine their practice habits, make connections between different skills and concepts, and provide a sense of ownership in their learning. The evaluation of students' performing the score in different ways on video, within the context of student-reported learning, enabled the instructor to respond to both the visible performance and the selfreported approaches that led to that result. Future conducting curricula should include multiple modes of assessing students' score study skills, practice habits, and concepts - for example, reflections, videos of students performing musical passages in different ways, peer feedback, and in-class performance assessments. While Silvey et al. (2016) previously recommended assessing a range of score study practices, this study has helped to make 
visible and provide insight into how several approaches contribute to student learning. Future authors of beginning conducting texts should consider how to more substantively integrate score study and larger conducting processes.

This study also has a number of implications for research. Conclusions from past research on undergraduate student score study topics were limited by both the brief length of time and isolation of skills examined. There is need for more studies that (a) capture score study practices over longer time periods and that (b) examine the ways various score study skills are integrated in support of important components of the conducting process, such as developing an aural image, nonverbal cues, error detection ability, and rehearsal strategies.

Limitations of this study also need to be considered. While data emerged from students' self-reporting on their progress, no comparison was made to an analysis of their conducting of the ensemble. Future studies that analyze the relationship between self-reported learning and assessment of skills may lead to a more comprehensive understanding of conductor development, resulting in additional implications for research and practice. Furthermore, data was drawn only from reflection assignments and examination questions; evaluating student learning using other research methods could result in additional insights. External and independent interviews that allowed for follow-up questions would enable a broader scope for both reflections and subsequent analysis. While the diversity of student reflections suggest independent thinking, it is possible that students aimed to capture the instructor's desired response. The limitations of sample size and singular location are also acknowledged here.

Researchers and pedagogues should continue to reevaluate the goals and methods used in conducting curricula and explore new possibilities that may lead to more comprehensive learning for students. The values that shape the design of student learning experiences should be given significant consideration. In their responses, students demonstrated a diverse range of professional goals, aiming to work as performers, teachers, composers, and producers, with very few stating a desire to become conductors. Regardless of their aspirations, the majority of students articulated how the skills they had learned enabled them to become better musicians and provided new ideas about how to practice and approach music.

The ability to learn, internalize, and develop a personal interpretation of a piece of music is essential for all musicians. While gesture is a critical tool for conductors, it is only as valuable as the ideas it communicates. Prioritizing score study in beginning conducting courses has the potential to profoundly impact students' musical development and inspire a deeper engagement within their own creative process.

\section{REFERENCES}

Battisti, F. L., \& Garofalo, R. (1990). Guide to score study for the wind band conductor. Meredith Music Publications.

Crowe, D. R. (1996). Effects of score study style on beginning conductors' error-detection abilities. Journal of Research in Music Education, 44, 160-171.

https://doi.org/10.2307/3345668

Donovan, M. S., Bransford, J. D., \& Pellegrino, J. W. (1999). How people learn: Bridging 
research and practice. National Academy Press.

Dweck, C. (2016). The remarkable reach of growth mind-sets. Scientific American Mind, 27(1), 36-41.

Feyes, A. D. (2017). The score study procedures of three collegiate wind band conductors (Doctoral dissertation). Retrieved from Electronic Theses, Dissertations, and Reports for Kansas State University. http://hdl.handle.net/2097/35424

Gumm, A. F. (2012). Six functions of conducting: A new foundation for music educators. Music Educators Journal, 99(2), 43-49. https://doi.org/10.1177/0027432112458705

Haimovitz, K., \& Dweck, C. (2017). The origins of children's growth and fixed mindsets: New research and a new proposal. Child Development, 88(6), 1849-1859.

https://doi.org/10.1111/cdev.12955

Hunsberger, D., \& Ernst, R. E. (1992). The art of conducting (2nd ed.). McGraw-Hill, Inc.

Kornelson, M. J. (2005). Finding the conductor's voice: A curricular framework for teaching choral conducting at the undergraduate level. The Phenomenon of Singing, 5, 168187. Retrieved from https://journals.library.mun.ca/ojs/index.php/singing/article/view/600/433

Labuta, J. A. (2004). Basic conducting techniques (5th ed.). Prentice-Hall, Inc.

Lane, J. S. (2006). Undergraduate instrumental music education majors' approaches to score study in various musical contexts. Journal of Research in Music Education, 54(3), 215230. https://doi.org/10.1177/002242940605400305

Maiello, A., \& Bullock, J. (1996). Conducting: A hands-on approach (2nd ed.). Alfred.

Manfredo, J. (2008). Factors influencing curricular content for undergraduate instrumental conducting courses. Bulletin of the Council for Research in Music Education, 175, 45-

62. Retrieved from http://www.jstor.org/stable/40319412

Mirakian, R. E. (2015). A graduate curriculum for orchestral conductors (Doctoral dissertation). Retrieved from http://hdl.handle.net/2022/19825

Mitchell, J. M. (2018). Score study procedures and processes among instrumental music teachers and students of varying experience (Master's thesis). Retrieved from Electronic Theses and Dissertations for University of Louisville. Paper 2962. https://doi.org/10.18297/etd/2962

O'Neill, S. A. (2011). Developing a young musician's growth mindset: The role of motivation, self-theories and resiliency. In I. Deliège \& J. W. Davidson (Eds.), Music and the mind: Essays in honour of John Sloboda (pp. 31-46). Oxford University Press.

Sheldon, D. A. (1998). Effects of contextual sight-singing and aural skills training on errordetection abilities. Journal of Research in Music Education, 46(3), 384-395. https://doi.org/10.2307/3345550

Silvey, B. (2011). Effects of score study on novices' conducting and rehearsing: A preliminary investigation. Bulletin of the Council for Research in Music Education, 187, 33-48. Retrieved from https://www.jstor.org/stable/41162322

Silvey, B. A., \& Baumgartner, C. M. (2016). Effects of nonverbal, verbal, and traditional rehearsal methods on ratings of conductor effectiveness and ensemble expressivity. Journal of Band Research, 51(2), 30-45. Retrieved from https://openmusiclibrary.org/article/16966/

Silvey, B. A., \& Montemayor, M. (2014). The effects of internal and external focus of attention on novices' conducting and rehearsal evaluations. Journal of Research in 
Music Education, 62, 161-174. https://doi.org/10.1177/0022429414530434

Silvey, B. A., Montemayor, M., \& Baumgartner, C. M. (2017). An observational study of score study practices among undergraduate instrumental music education majors. Journal of Research in Music Education, 65(1), 52-71. https://doi.org/10.1177/0022429416688700

Silvey, B. A., Springer, D. G., Eubanks, S. C. (2016). An examination of university conducting faculty members' score study attitudes and practices. Journal of Music Teacher Education, 26(1), 82-95. https://doi.org/10.1177/1057083715616442

Stewart, T. E. (2011). Beginning conducting curricula: Building course objectives upon the foundations of aural image and natural body movement (Doctoral dissertation). Retrieved from ETD collection for University of Nebraska - Lincoln. (AAI3450121)

Thomas, D. R., (2006). A general inductive approach for analyzing qualitative evaluation data. American Journal of Evaluation, 27(2), 237-246. http://dx.doi.org/10.1177/1098214005283748

Ulrich, J. (2009). Preparing the conductor as teacher. Music Educators Journal, 95(3), 48-52. https://doi.org/10.1177/0027432108330798

Zirkman, R. A. (1984). Review of educational objectives for conducting classes for the undergraduate through the doctoral degree (Doctoral dissertation). (Order No. 8423047). Retrieved from ProQuest Dissertations \& Theses Global. (303319174)

BRIAN KAUFMAN is an Associate Professor at the University of Maryland Baltimore County (UMBC) where he leads conducting classes, the wind ensemble, and the music education program. His work has led to performances and presentations across five continents at institutions including the United Nations, the Ford Foundation, and Yale University.

NELL FLANDERS holds the position of Princeton Symphony Orchestra's Georg and Joyce Albers-Schonberg Assistant Conductor. She conducts the Symphony Orchestra at the Manhattan School of Music Precollege Division and The Chelsea Symphony in NYC and holds degrees from Oberlin, Mannes, and a DMA in orchestral conducting from Peabody Conservatory. 